\title{
Project Guide to Coding in Nvivo and Codebook
}

Ashwin Ravikumar

Rodd Myers

Laura Kowler

Jazmín Gonzales Tovar

Supplement document for

Ravikumar A, Kijazi M, Larson AM and Kowler L. 2015.

Project Guide and Methods Training Manual. Guideline. Bogor, Indonesia: CIFOR. 
Guideline

(c) 2015 Center for International Forestry Research

(c) (i) Content in this publication is licensed under a Creative Commons Attribution 4.0 International (CC BY 4.0), http://creativecommons.org/licenses/by/4.0/

ISBN 978-602-1504-88-8

DOI: $10.17528 /$ cifor/005542

Ravikumar A, Myers R, Kowler L and Tovar JG. 2015. Project Guide to Coding in Nvivo and Codebook. Guideline. Bogor, Indonesia: CIFOR.

Corresponding author Ashwin Ravikumar - ashwin.r@cgiar.org

CIFOR

J. CIFOR, Situ Gede

Bogor Barat, 16115

Indonesia

$\mathrm{T}+62(251) 8622-622$

$\mathrm{F}+62(251) 8622-100$

E cifor@cgiar.org

\section{cifor.org}

We would like to thank all donors who supported this research through their contributions to the CGIAR Fund. For a list of Fund donors please see: https://www.cgiarfund.org/FundDonors

Any views expressed in this publication are those of the authors. They do not necessarily represent the views of CIFOR, the editors, the authors' institutions, the financial sponsors or the reviewers. 


\section{Contents}

How to Code

Classifying your Interview

The Nodes 


\section{Guide to Coding}

The purpose of this working document is to describe our system for importing, classifying, and coding your data from the field in Nvivo. The attached codebook provides information on the specific codes that were developed for this project. These codes must necessarily be altered somewhat to adapt to specific research questions and contexts. For a copy of the Nvivo node tree and further information on how to apply them, please contact the corresponding author (Ashwin Ravikumar - ashwin.r@cgiar.org).

\section{How to Code}

Learning to code your data is an iterative process, and it will become much faster once you have coded several interviews. Especially towards the beginning, please consult with other team members - either your country supervisor or the Lima team - liberally as you become familiar with the procedures.

In general, the different nodes are labeled to describe their intent, and what types of responses should be coded at them. Otherwise, this document is your guide on how to code, and what each node is for. When I code qualitative data, I ask myself the following questions frequently as I proceed:

- What analytical questions might I ask myself later that this text would help me answer?

- When we are doing analysis later, and want to know about , is this text coded in such a way that we will be able to easily retrieve it with an obvious query?

- $\quad$ Are there any other analytical questions that we might have later that this question may be useful in answering besides my first instinct?

Below, the different nodes are described, followed by an important section on cross-coding with actors.

\section{Classifying your Interview}

Before you get into substantive coding, you should code the entire interview on basic attributes: country, instrument used (key informant, benefit sharing survey, or ethnography), region/province, district/local administrative subdivision, interviewer (that's you), and case name. For the case name, name your cases systematically. We recommend that each case be assigned a number for reference. For example, we might name cases from San Martin SM1- Barranquita Oil palm, SM2- PNCA REDD+, etc. cases in Central Kalimantan might be CK1-KFCP REDD+, CK2- RMU REDD+, etc., and cases from Ucayali could be UCA1- Padre Abad Oil Palm, UCA2- AIDER REDD+, etc. The particular naming scheme that you choose is left to your discretion.

To classify each interview, highlight the entire text of the interview, and code it to the appropriate classifying nodes according to the procedure above. 


\section{The Nodes}

This section describes all current coding nodes, and how to use them. The blue nodes must be cross-coded with an actor from the "Actor Mention" section. Other nodes should NOT be cross-coded with an actor from Actor Mention. In general, if a piece of text from an interview seems to have multiple nodes that it could be coded to, the best practice is to code it at all relevant nodes. Moreover, try to think about all possible contexts in which a piece of text may be relevant. For example, text dealing with land use history might also be highly relevant to an analysis later that focuses on conflict between levels of government. Make sure to code it in such a way that you or someone else doing analysis later can retrieve it for any analysis that it is relevant for.

\section{NVivo Code Table}

\begin{tabular}{|c|c|}
\hline Name & Information \\
\hline Accountability & $\begin{array}{l}\text { Code responses where the respondent discusses accountability of land use decision- } \\
\text { making processes here. This should be construed broadly, including mechanisms of } \\
\text { accountability, and perceptions of accountability. However, it should NOT include } \\
\text { accountability in processes BENEFIT SHARING - that must be coded LATER. }\end{array}$ \\
\hline Actor Mention & $\begin{array}{l}\text { This category is ONLY for cross-coding. Items in BLUE below should be cross-coded } \\
\text { with the relevant actor under Actor Mention. It is important to ONLY cross-code the } \\
\text { blue items below with actors, as otherwise the folks doing analysis will not know } \\
\text { what to cross-query, and your coding may not be put to use. }\end{array}$ \\
\hline ADATTraditional Leadership & Indonesia only \\
\hline \multicolumn{2}{|l|}{$\begin{array}{l}\text { CBC Community Based } \\
\text { Committee }\end{array}$} \\
\hline \multicolumn{2}{|l|}{$\begin{array}{l}\text { CMFC Community Managed } \\
\text { Forest Committee }\end{array}$} \\
\hline \multicolumn{2}{|l|}{ COAL Coalition of Actors } \\
\hline \multicolumn{2}{|l|}{ CONCESSION Holder(s) } \\
\hline \multicolumn{2}{|l|}{ CORP Private Company } \\
\hline \multicolumn{2}{|l|}{ DONR Donors } \\
\hline \multicolumn{2}{|l|}{ FARM Farmer org or coop } \\
\hline \multicolumn{2}{|l|}{ GOV1 National } \\
\hline \multicolumn{2}{|l|}{ GOV2 Province (Region) } \\
\hline \multicolumn{2}{|l|}{ GOV3 District (Province) } \\
\hline \multicolumn{2}{|l|}{ GOV4 Subdistrict } \\
\hline GOV5 Village or Community & Village or community GOVERNMENT \\
\hline \multicolumn{2}{|l|}{ GOV6 Actor below village level } \\
\hline \multicolumn{2}{|l|}{$\begin{array}{l}\text { GOVG Multi-level Government } \\
\text { Group }\end{array}$} \\
\hline \multicolumn{2}{|l|}{ IACT Independent Activist } \\
\hline \multicolumn{2}{|l|}{ IND Indigenous Organization } \\
\hline LOBY Private Lobbyist & \\
\hline
\end{tabular}




\section{Name}

MSME Small Enterprise

\section{Information}

Micro, small and medium enterprises can include small-scale miners, small agrircultural businesses, and other small businesses. It is likely that a MSME actor is also a smallholder, although they may be a private firm - if necsessary, double code

NGOI International NGO

NGOL Local NGO

NGON National NGO

RINI International Research

Institute

RINN National Research

Institute

\begin{tabular}{|c|c|}
\hline SMHOLD Smallholders & Smallholder farmers themselves \\
\hline $\begin{array}{l}\text { Articulation and } \\
\text { Communication }\end{array}$ & $\begin{array}{l}\text { Code responses, such as from KI 14, about articulation and communication between } \\
\text { levels of government and other actors as below here, EXCEPT IN THE CONTEXT OF } \\
\text { BENEFIT SHARING AS THAT HAS A SEPARATE NODE }\end{array}$ \\
\hline AC Other & $\begin{array}{l}\text { Code other descriptions of information flow and articulation between actors. THIS } \\
\text { IS AN IMPORTANT CODE THAT SHOULD CAPTURE ALL COMMUNICATION AND } \\
\text { ARTICULATION BETWEEN ACTORS APART FROM WHAT FITS IN THE OTHER SPECIFIC } \\
\text { NODES ON INTER-LEVEL COMMUNICATION }\end{array}$ \\
\hline AC RegDist & $\begin{array}{l}\text { Code information about information flow and articulation between regional and } \\
\text { local government here }\end{array}$ \\
\hline AC RegNat & $\begin{array}{l}\text { Code information about information flow and articulation between regional and } \\
\text { provincial government here }\end{array}$ \\
\hline AC RegProv & $\begin{array}{l}\text { Code information about information flow and articulation between regional and } \\
\text { national government here }\end{array}$ \\
\hline Authority & $\begin{array}{l}\text { Different roles, powers, responsibilities, and purviews related to land use and other } \\
\text { areas are nested here. All must be cross-coded with the actor who the respondent } \\
\text { describes as having that authority. }\end{array}$ \\
\hline Authority- Horizontal & $\begin{array}{l}\text { Issues of power relations and decision making authority among horizontal levels of } \\
\text { government }\end{array}$ \\
\hline \multicolumn{2}{|l|}{ Authority-Land use decisions } \\
\hline - Authority- LUD- Agriculture & \\
\hline $\begin{array}{l}\text { - Authority- LUD- } \\
\text { Concessions }\end{array}$ & Code here for concessions of all types \\
\hline - $\quad$ Authority- LUD- Forest & \\
\hline $\begin{array}{l}\text { - Authority- LUD- Indigenous } \\
\text { land }\end{array}$ & \\
\hline - Authority- LUD-Industry & \\
\hline $\begin{array}{l}\text { - } \text { Authority- LUD- } \\
\text { Infrastucture }\end{array}$ & \\
\hline - Authority- LUD- Mining & Code here for NON-HYDROCARBON mining \\
\hline - Authority- LUD- Oil & Code here for oil AND OTHER HYDROCARBONS \\
\hline
\end{tabular}




\section{Name}

- $\quad$ Authority- LUD Planning and Zoning

\section{Information}

Code here for actors involved in any planning or zoning. If a response suggests an authority that involves planning and zoning, but also another sector or activity such as titling, indigenous lands, or even agriculture - you should TRIPLE CODE it.

- Authority- LUD- Plantations

- Authority- LUD- Protected Areas

- $\quad$ Authority- LUD- Ranching

- Authority- LUD-REDD+ • Code here for actors involved in REDD+ POLICY (all levels) Policy

- Authority- LUD REDD+ Code here for actors involved in REDD+ PROJECTS planning or implementation Project Planning or Implementation

- $\quad$ Authority- LUD Titling

- Code here for actors involved in titling lands of any type. If an actor is noted as having responsibility over titling a PARTICULAR type of land - for example, concessions or indigenous lands - you should TRIPLE CODE it.

\begin{tabular}{l} 
Authority- Other \\
- Authority- infrastructure \\
\hline - Authority- Permits \\
\hline Authority-Traditional
\end{tabular}

\section{Benefit Sharing}

BS Accountability

BS Aspirations
BS Capacity Change

BS Challenges

- BS Conflicts Among Actors
Traditional authorities including adat in Indonesia, other traditional authority elsewhere
All nodes related to benefit sharing are nested here

Code all information dealing with accountability mechanisms and processes here, including recourses available to actors if another actor reneges on a contractual agreement. Conflict resolution mechanisms should also be coded here. Hopes that people have from the BS arrangement that have not yet materialised The nodes representing the different types of 'capacity change' from the question on the BS survey are nested under this node. Code the responses to the appropriate node based on the response to the question.

Specific challenges that the BS arrangement faces are nested here

Code responses that indicate any type of conflict among actors. This could be, for example, between households in a project village, between a private firm and communities, between levels or divisions of government, or between NGOs and other actors. Conflict can, of course, arise as a result of the other challenges. Lack of political will, lack of funds, or low capacity, for example, generate - or be inextricably linked - to conflict. Thus, cross-code conflict with other relevant challenges.

- BS Different interpretations Code responses that indicate that there are issues arising from different actors having different interpretations of the purpose, nature, or activities of the arrangement. This includes issues arising from lack of clarity in laws, norms, and de facto rules, or overlapping roles and responsibilities.

- BS Lack of Funds Code responses that indicate insufficient funds for designing, managing, or implementing the BS arrangement here

- BS Lack of Information
Code responses that indicate lack of information among any actors as a challenge here. This can also include misinformation. Remember to double code 


\section{Name}

- $\quad$ BS Lack of Interest

- BS Lack of Political Will

\section{Information}

Code responses that indicate lack of interest among key stakeholders in the benefit sharing arrangement or associated activities

Code responses that indicate lack of political will, including for example lack of buyin from participants

- BS Low capacity

Code responses that indicate lack of capacity here, such as insufficient trained personnel or human resources

BS Conflict Resolution

Mechanism

Responses that deal with how conflicts are resolved when they arise, or how they play out. If there are conflicts in the design OR implementation of benefit sharing, they can be coded here.

\begin{tabular}{ll} 
BS Contract & Code responses detailing whether or not - and if so what sort - of contract exists \\
\hline BS Contractual Recourse & Responses describing what one actor can do to respond if there is a breach of \\
& $\begin{array}{l}\text { contract. If someone isn't paid what they are owed, what can they do about it, or } \\
\text { example? }\end{array}$
\end{tabular}

BS Dependency

- BS Dependency - BSA Responses to question on peoples' dependence on the benefit sharing arrangement

- BS Dependency - Natural Resources

BS Information Responses to question on peoples' dependence on natural resources in general

BS Interest Change Code responses related to how information is shared between actors. If information sharing or quality of information is flagged as a challenge, remember to double code under BS Challenges- Lack of Information (described below). Code responses that indicate that actors' interests have changed related to or due to the benefit sharing arrangement (potentially as a result of exclusion or inclusion)

BS Law Code responses that speak to the status of benefit sharing laws (nonexistent, in development, or community-based statute without formalized law by districts, regions, provinces, or national government).

\begin{tabular}{ll} 
- & BS Law Exists \\
\hline - & BS Law In Development \\
\hline
\end{tabular}
Code here for descriptions of laws pertaining to benefit sharing Descriptions of laws in development Code here for responses that indicate that there is neither a law nor an informal arrangement/set of norms governing the rights and responsibilities associated with the benefit sharing arrangements. This includes mentions of laws being "in development," as they do not yet exist.

- $\quad$ BS Norm Exists Code here for descriptions of informal norms or arrangements that assign roles and responsibilities associated with the benefit sharing arrangement.

- Community-based statute If there is a community-based statute, code here

BS Management

Nodes that describe the role of communities in management of the benefit sharing arrangement are nested here. Note that these categories were developed largely based on theory, and preliminary findings suggest that the distinctions may not be so clear in reality. If there is a description of how the benefit sharing arrangement is managed, code it to the category that BEST fits the description.

- BS ManagementCommunity-based

Code responses that suggest broad community control over management

- BS ManagementConsigned
Code responses that suggest communities engage in consigned management 


\section{Name}

- BS ManagementConsultation

- BS ManagementCooperative

- BS Management- Other

- BS ManagementPartnerhsip

BS Negotiation

\section{Information}

Code responses that suggest communities are consulted here

Code responses that suggest communities cooperatively participate in management with some responsibilities

Code responses that suggest communities jointly manage the arrangement with another actor

Code responses here dealing with WHO WANTED WHAT, and WHO GOT WHAT. This includes the process of how those outcomes were reached.

- BS Negotiation difference of Code negotiation issues that suggest differences of opinion opinion

- BS Negotiation resolutions Code negotiation issues that detial how the difference of opinion was resolved to differences

BS Participating Actors Cross-code with actors who participated in the design, management, or implementation of the benefit sharing arrangement.

- Excluded actors

Cross-code with actors who were EXCLUDED or did NOT participate in the design, management, or implementation of the benefit-sharing agreement

BS Participation Level

0. No BS Participation

1. Low BS Participation

2. Medium BS Participation

3. High BS Participation

BS Participation Mechanism

Code responses that deal with the mechanism for securing participation in the design or governance of the benefit sharing arrangement

BS Scale Geographic extent of benefit sharing arrangement is discussed

BS Stage Advancement of BS arrangement

- BS Arrangement not yet completed

Code indications that the benefit sharing arrangement has not yet been completed or is still in development here

- BS Completed

Code indications that the benefit sharing arrangement is complete here - that is, it has been agreed upon by relevant parties

BS Sustainability Code responses dealing with how sustainable the benefit sharing arrangement is. Are sources of funding secure for the long term?

BS Type Code indications of the type of benefit being shared

- Burden Any burdens that are shared - along with benefits - should be coded here

- Direct Monetary Benefit) Indications of direct monetary benefits should be coded here

- Indirect (Non-Monetary Benefit)

- Access to resources

- Capacity Building and Training 


\begin{tabular}{|c|c|}
\hline \multicolumn{2}{|c|}{ Name } \\
\hline$\cdot$ & Certification \\
\hline - & Cultural protection \\
\hline - & $\begin{array}{l}\text { Ecosystem } \\
\text { improvement }\end{array}$ \\
\hline - & Forest Protection \\
\hline$\cdot$ & Infrastructure \\
\hline$\cdot$ & Jobs \\
\hline$\cdot$ & Other \\
\hline$\cdot$ & Technical Assistance \\
\hline$\cdot$ & Tenure \\
\hline
\end{tabular}

Coalitions

Code responses where respondents describe actors that they cooperate with or are in coalition with

\section{Drivers}

Drivers of DD

Drivers of improvement

- Effectiveness

1. Low Effectiveness

2. Medium Effectiveness

3. High Effectiveness

- Required actions to reduce DD

\section{General Highlights \\ Government and Context}

\section{Incentives for Behavior}

\begin{tabular}{ll}
\hline Economic Incentive & Indications of Land use change incentivized economically \\
\hline Legal Incentive & Code indications of decisions being motivated by law \\
\hline Political Incentive & $\begin{array}{l}\text { Code indications of political incentives including votes, coalition-building, securing } \\
\text { more power, or being made to by political leverage }\end{array}$ \\
\hline Land Use &
\end{tabular}

\section{Land Use}

CURRENT Land Condition, Use, Code descriptions of CURRENT land use and Activities

Code responses where respondents describe drivers of deforestation and actors responsible for deforestation, forest degradation, and progress towards increasing emissions from land use change here. Cross-code with actor responsible for the driver of deforestation.

Code responses where respondents note drivers of "improvement." Actors responsible for movement towards decreasing emissions from land use here such as reforestation, conservation, or other REDD+ activities

Code responses about how effective activities aimed at reducing deforestation and forest degradation are

Code respondents' perspectives on what would be required to really reduce deforestation and forest degradation here.

Key quotes on any topic

Nodes related to government activities, conflicts between levels and sectors of government, and changes in government roles and responsibilities in general - this category is for information about the overall context of government, not necessarily related to our case studies. 
NVivo Code Table - Continued

\section{Name \\ Information}

Direction of Land Use Change Code indications of the direction of land use change

Land Ownership and Tenure Ownership and tenure - any reference to the nested types

- Land Use Change Consequence

Code responses describing the consequences of land use change. This is construed broadly. If they describe economic consequences, livelihoods consequences, environmental consequences, or governance consequences, or tenure consequences, these responses can be coded to this node. Further analysis can parse these finer distinctions later.

- Land Use Conflict

Code descriptions of land use conflict here. As with land use history, this is to be construed broadly, and may encompass longer texts describing conflicts in detail. These are very useful for reports later on, and more granular analyses can be conducted later.

- Land Use History

Code responses that generally describe history of land use at a site here. This comes out of all instruments, but often the ethnography. This node may have very long texts or sections of transcripts coded to it at once. This is okay, as the histories will need to be traced in later analyses, and are moreover useful for regional and country reports. Note that there are several items nested under this that are more specific, dealing with carbon emissions from land use. Where responses relate histories that speak specifically to such issues, code them there. Other responses dealing with land use history more generally should be coded here.

- Land Use Scale Code the scale/geographic extent of the land use

- Community

- Landscape

- Watershed

- PREVIOUS Land Condition, Code descriptions of PREVIOUS land use Use, and Land Use Activities

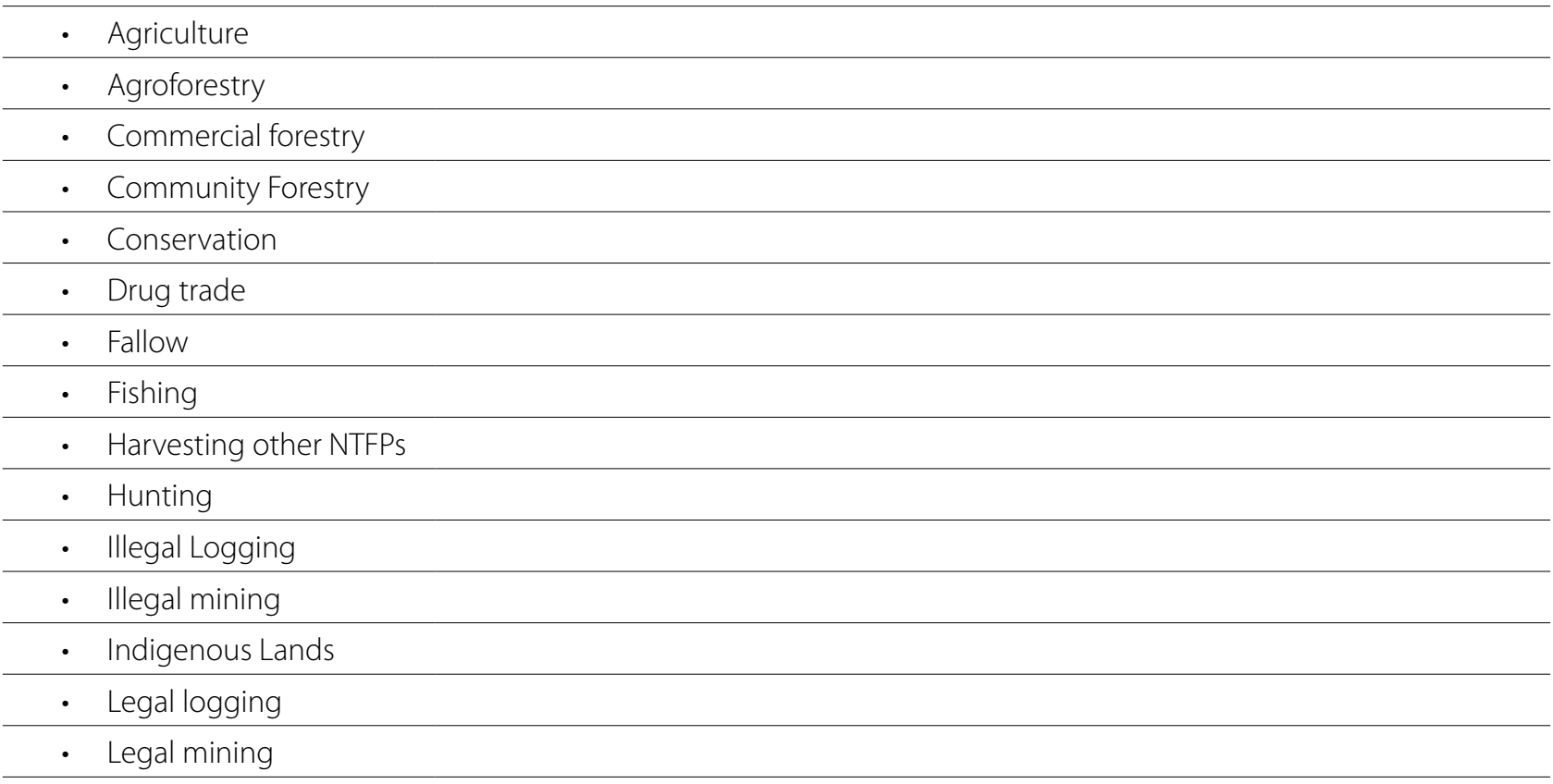




\begin{tabular}{ll} 
Name & Information \\
\hline & Livestock \\
\hline$\cdot$ Oil palm \\
\hline$\cdot$ Other \\
\hline$\cdot$ Pasture \\
\hline$\cdot$ Plantation \\
\hline$\cdot$ Primary forest \\
\hline$\cdot$ Secondary forest \\
\hline • & Tourism \\
\hline & doomestic use
\end{tabular}

\begin{tabular}{|c|c|}
\hline \multicolumn{2}{|l|}{ Legitimacy } \\
\hline Legitimacy- Outcome & Code responses that deal with outcome legitimacy of land use related decisions here \\
\hline \multicolumn{2}{|l|}{$\begin{array}{l}\text { Legitimacy- } \\
\text { Outcome- trust and } \\
\text { communication }\end{array}$} \\
\hline - Legitimacy- Procedural & $\begin{array}{l}\text { Code responses that deal with procedural legitimacy of land use related decision } \\
\text { processes here }\end{array}$ \\
\hline $\begin{array}{l}\text { Multilevel Governance } \\
\text { Highlights }\end{array}$ & Key quotes and succinct notes on multilevel governance institutions and dynamics \\
\hline Respondent Background & $\begin{array}{l}\text { Information about the respondent's background including education, profession, } \\
\text { and origin should be coded here }\end{array}$ \\
\hline Source Attributes & Code for all cases interviews/sources \\
\hline \multicolumn{2}{|l|}{ Understanding of REDD+ } \\
\hline \multicolumn{2}{|l|}{$\begin{array}{l}\text { - REDD+ Opinions and } \\
\text { Perspectives }\end{array}$} \\
\hline $\begin{array}{l}\text { - Understanding- A ( No } \\
\text { Conditions) }\end{array}$ & $\begin{array}{l}\text { For respondents who perceive REDD+ as about carbon emissions reductions without } \\
\text { any conditions }\end{array}$ \\
\hline $\begin{array}{l}\text { - Understanding- B (With } \\
\text { Safeguards) }\end{array}$ & $\begin{array}{l}\text { For respondents who perceive REDD+ as about carbon emissions reductions with } \\
\text { safeguards (social and otherwise) }\end{array}$ \\
\hline $\begin{array}{l}\text { - Understanding- C (Low C } \\
\text { Emission with Livelihoods) }\end{array}$ & $\begin{array}{l}\text { For respondents who perceive REDD+ as about carbon emissions reductions with } \\
\text { BENEFITS to livelihoods also occurring }\end{array}$ \\
\hline $\begin{array}{l}\text { - Understanding- D } \\
\text { (Livelihoods \& Tenure Result } \\
\text { in Lower C Emission) }\end{array}$ & $\begin{array}{l}\text { For respondents who perceive REDD+ as a means supporting livelihoods, with a } \\
\text { side-effect of carbon emissions reductions. If carbon doesn't even factor into their } \\
\text { perception of REDD+, and they perceive it as purely livelihoods-related, code here } \\
\text { as well. If such responses are very common, we can parse them out later. There is } \\
\text { indeed a preliminary expectation that this livelihoods-centric view, with little to no } \\
\text { consideration of carbon, will be quite common, and perhaps even dominant in some } \\
\text { areas. Code all such responses here, and further detail can then be ascertained later. }\end{array}$ \\
\hline - Understanding- Not Sure & \\
\hline
\end{tabular}


